\title{
Microarray-Based Transcriptional Profiling of Renieramycin $M$ and Jorunnamycin C, Isolated from Thai Marine Organisms
}

\author{
Kornvika Charupant ${ }^{1}$, Khanit Suwanborirux ${ }^{1, *}$, Naomi Daikuhara ${ }^{2}$, Masashi Yokoya ${ }^{2}$, Rie \\ Ushijima-Sugano $^{3}$, Takatoshi Kawai ${ }^{3}$, Takashi Owa ${ }^{3, *}$ and Naoki Saito ${ }^{2, *}$ \\ 1 Department of Pharmacognocy and Pharmaceutical Botany, Center for Bioactive Natural Products \\ from Marine Organisms and Endophytic Fungi (BNPME), Faculty of Pharmaceutical Sciences, \\ Chulalongkorn University, Pathumwan, Bangkok 10330, Thailand \\ 2 Graduate School of Pharmaceutical Sciences, Meiji Pharmaceutical University, 2-522-1 Noshio, \\ Kiyose, Tokyo 204-8588, Japan \\ 3 Tsukuba Research Laboratories, Eisai Co. Ltd., 5-1-3 Tokodai, Tsukuba, Ibaraki 300-2635, Japan \\ * Author to whom correspondence should be addressed; E-Mails: skhanit@chula.ac.th (K.S.); \\ t-owa@hhc.eisai.co.jp (T.O.); naoki@my-pharm.ac.jp (N.S.); Tel./Fax: +66-2218-8357 (K.S.); \\ Tel./Fax: +81-29-847-7614 (T.O.); Tel./Fax: +81-42-495-8794 (N.S.).
}

Received: 26 August 2009; in revised form: 14 October 2009 / Accepted: 19 October 2009 / Published: 19 October 2009

\begin{abstract}
Renieramycin $\mathrm{M}$ and jorunnamycin $\mathrm{C}$, two isoquinolinequinone compounds differing only at the C-22 ester side chain, were evaluated for their cytotoxic effects on human colon (HCT116) and breast (MDA-MB-435) cancer cell lines. These two compounds displayed potent cancer cell growth inhibition, their $\mathrm{IC}_{50}$ values reaching nanomolar order. To examine their effects on transcription, we carried out oligonucleotide microarray analysis with focus on the similarities and differences between the two compounds in terms of transcriptional profiles. We found that the down-regulation of PTPRK (protein tyrosine phosphatase receptor type $\mathrm{K}$ ) can be considered as a biomarker responsive to the cytotoxic effects of this class of antitumor marine natural products.
\end{abstract}

Keywords: renieramycin M; jorunnamycin C; marine sponge; oligonucleotide microarray; antitumor agent 


\section{Introduction}

Tetrahydroisoquinolinequinones and their reduced forms have attracted considerable interest over the past 30 years due to their potent biological activities [1]. A great many such natural products have been isolated, predominantly from Actinomycetes and marine organisms. On the basis of their characteristic structures, antibiotics could be subdivided into three categories: (1) naphthyridinomycins, cyanocyclines, and bioxalomycins, (2) saframycins and safracins, and (3) quinocarcins, tetrazomine, and lemonomycin. Meanwhile, marine natural products can be subdivided into two categories: (1) renieramycin, cribrostatin, jorumycin, and jorunnamycin and (2) ecteinascidins (Figure 1). The most bioactive member of marine natural isoquinoline family, ecteinascidin 743 (Yondelis, trabectedin), has a unique mechanism of action in that its binds to the minor groove of DNA to interfere with cell division, activated transcription, and DNA repair [2-9]. Ecteinascidin 743 has been approved by the European Commission for use in advanced soft tissue sarcoma patients who do not respond to anthracyclines and ifosfamide, or who are unsuited to receive these agents. The remarkable results of preclinical and clinical trials of ecteinascidin 743 have stimulated further research of this class of antitumor agents, including PM00104 (Zalypsis) [10,11], phthalascidin (Pt 650) [12], and QAD [13] (Figure 2).

Figure 1. Structures of renieramycins, jorunnamycins, and related marine natural products with significant antiproliferative activity.

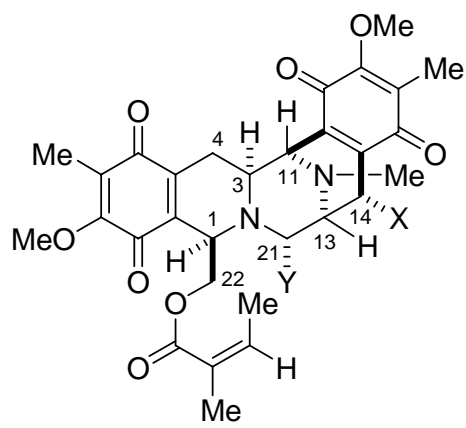

renieramycins

$\mathrm{E}: \mathrm{X}=\mathrm{H}, \mathrm{Y}=\mathrm{OH}$

$\mathrm{F}: \mathrm{X}=\mathrm{OMe}, \mathrm{Y}=\mathrm{OH}$

$\mathrm{M}: \mathrm{X}=\mathrm{H}, \mathrm{Y}=\mathrm{CN}$

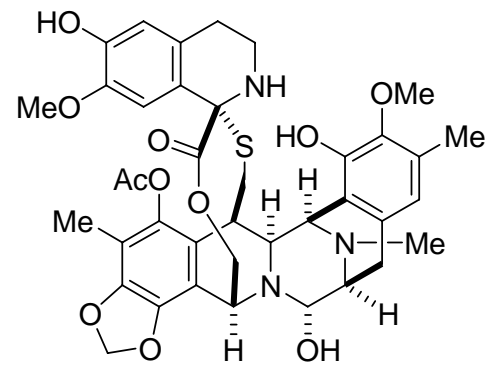

Ecteinascidin 743

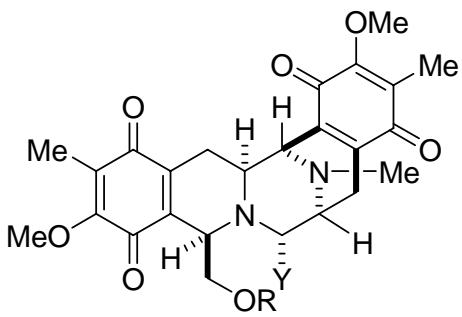

Jorumycin: $\mathrm{R}=\mathrm{COMe}, \mathrm{Y}=\mathrm{OH}$ Jorunnamycins

A: $R=H, Y=C N$

$\mathrm{C}: \mathrm{R}=\mathrm{COEt}, \mathrm{Y}=\mathrm{CN}$

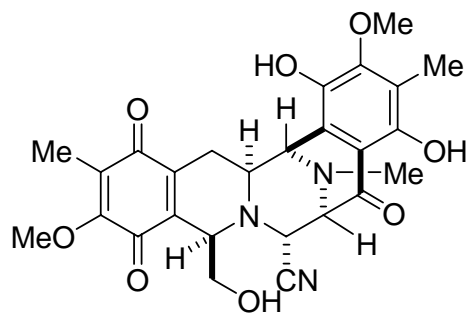

Jorunnamycin B 
Renieramycins E and F were isolated from Reniera sp. by Faulkner's group in 1989 [14,15]. These two compounds, whose ring system and the relative stereochemistry are identical those of saframycin A, exhibit strong cytotoxicity toward cultured cells in vitro and antitumor activity against several experimental tumors in vivo. Jorumycin, which was discovered in very minute quantities from the mantle and mucus of the Pacific nudibranch Jorunna funebris, possesses growth inhibitory activity against various human cancer cell lines [16]. These three compounds have a relatively unstable carbinolamine group that may decomposed during isolation process, thus, they are available in only minute quantities from natural sources.

In our search for new metabolites via the isolation and characterization of biologically active compounds from Thai marine animals, we succeeded in the isolation and structure elucidation of renieramycin $\mathrm{M}$, which is a stable congener of renieramycin $\mathrm{E}$ with $\alpha$-aminonitrile group instead of calbinolamine group, from the Thai sponge, Xestospongia sp., by pretreatment with potassium cyanide $[17,18]$. We realized the gram-scale supply of renieramycin-type compounds using our procedure, and recently reported significant results gained from the extension of our initial investigation and the results of cytotoxicity evaluation of C-22 ester analogues and a very promising compound, the 2'-pyridinecarboxylic acid ester derivative [19] (Figure 2). We also reported the isolation of jorunnamycins A-C from the mantles, visceral organs, and egg ribbons of the Thai nudibranch Jorunna funebris, following the same procedure that used potassium cyanide [20].

Figure 2. Structures of synthetic analogues maintaining significant high cytotoxicity.
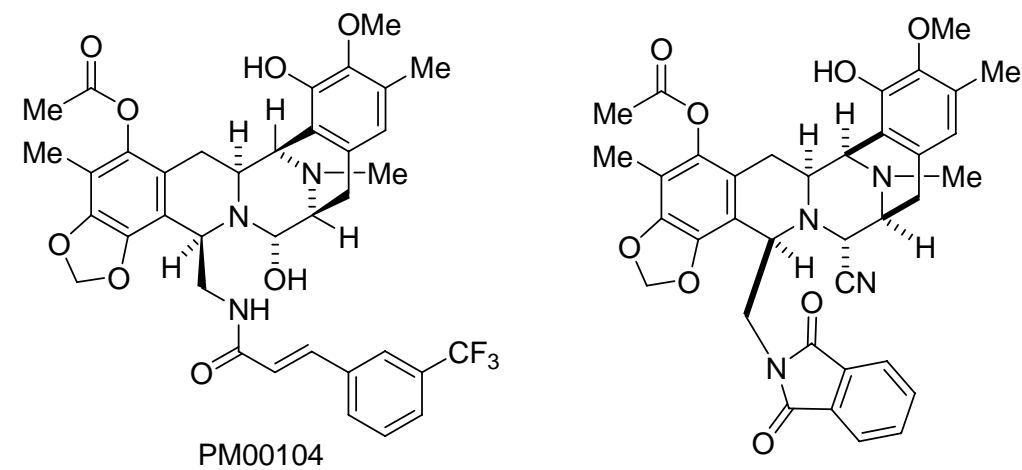

Phthalascidin
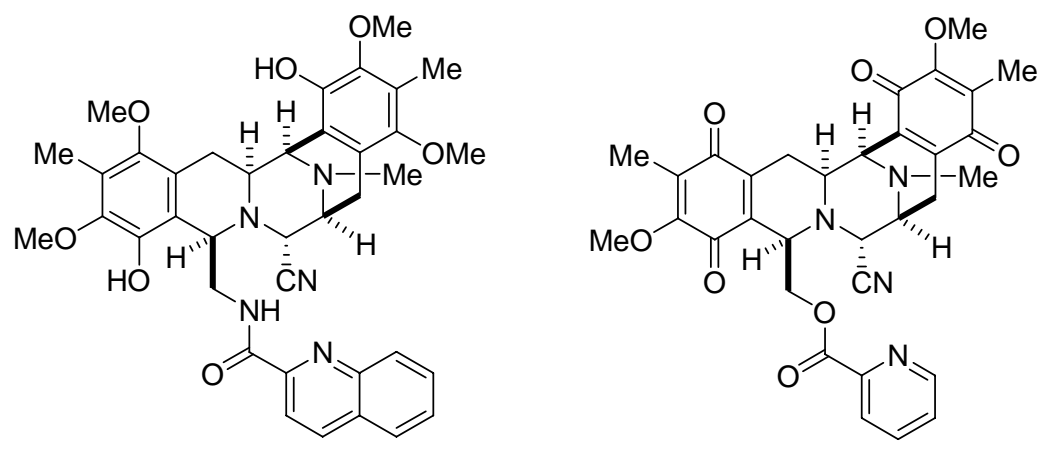

QAD 
Described herein is a significant extension of our initial investigation of renieramycin $\mathrm{M}$ and jorunnamycin C, cyano-group containing isoquinolinequinone ester analogues. We used oligonucleotide microarray analysis to clarify the effects of these two compounds on cellular transcription. We focused on transcriptional SAR (structure and activity relationship) studies to identify a potential gene expression marker(s) that is closely associated with the antitumor activity of these fascinating marine natural products.

\section{Results and Discussion}

Renieramycin $\mathrm{M}$ and jorunnamycin $\mathrm{C}$ were isolated from potassium cyanide pretreated sponge, Xestospongia sp., and nudibranch, Jorunna funebris, respectively. Human cancer cell lines HCT116 (colon) and MDA-MB-435 (breast) were grown in RMPI 1640 (Sigma) containing supplements that included $10 \%(\mathrm{v} / \mathrm{v})$ heat-inactivated fetal bovine serum (Equitech-BIO) and a solution of $100 \mathrm{U} / \mathrm{mL}$ penicillin and $100 \mu \mathrm{g} / \mathrm{mL}$ streptomycin (Invitrogen). Cell culture was performed at $37{ }^{\circ} \mathrm{C}$ in a humidified atmosphere of $5 \% \mathrm{CO}_{2}$ and $95 \%$ air.

After continuous exposure of these compounds for three days, the concentration required for $50 \%$ growth inhibition $\left(\mathrm{IC}_{50}\right)$ was determined by the MTT colorimetric assay [21]. The results are presented in Table 1 . In this assay, renieramycin $M$ was more potent than jorunnamycin $C$ (by approximately twofold on $\mathrm{IC}_{50}$ basis) against human HCT116 colon and MDA-MB-435 breast cancer cell lines [22].

Table 1. Antiproliferative activity of renieramycin $M$ and jorunnamycin $C$ against HCT116 and MDA-MB-435 human cancer cell lines.

\begin{tabular}{lcc}
\hline & \multicolumn{2}{c}{ Human cancer cell line, IC $_{\mathbf{5 0}} \pm$ SD (nM) } \\
\cline { 2 - 3 } Compound & HCT116 (colon) & MDA-MB-435 (breast) \\
\hline Renieramycin M & $16.4 \pm 0.3$ & $6.3 \pm 0.1$ \\
Jorunnamycin C & $27.3 \pm 1.0$ & $16.3 \pm 1.3$ \\
\hline
\end{tabular}

In order to compare renieramycin $\mathrm{M}$ and jorunnamycin $\mathrm{C}$ on the basis of their transcriptional signatures, we analyzed the expression changes of more than 8,500 transcripts in HCT116 and MDA-MB-435 cells using Affymetrix Human Genome Focus arrays. The investigated time points were $4 \mathrm{~h}$ and $12 \mathrm{~h}$. All data were obtained in triplicate to verify statistical significance [23].

The hierarchical clustering data on the dendrogram format and the cosine coefficients between any two data points on the table format are shown in Figure 3. This analysis revealed that renieramycin M and jorunnamycin $\mathrm{C}$ have similar effects on the gene expression of each human cancer cell line and also at each time point (cosine coefficients: 0.66 in the 4-h treatment for HCT116; 0.57 in the 12-h treatment for HCT116; 0.74 in the 4-h treatment for MDA-MB-435; and 0.76 in the 12-h treatment for MDA-MB-435). The high correlation indicates that both compounds operate via essentially the same primary mechanism(s) of action, particularly in MDA-MB-435, a more sensitive cancer cell line to these antitumor agents. 
Figure 3. Correlation between transcriptional signatures of renieramycin $M$ and jorunnamycin C. With respect to two human cancer cell lines (HCT116 and MDA-MB-435) and two time points (4 h and $12 \mathrm{~h}$ ), hierarchical clustering data on the dendrogram format and cosine coefficient data on the table format are presented. Abbreviations: RM, renieramycin M; JC, jorunnamycin C; HCT, HCT116; MDA, MDA-MB-435; CC, correlation coefficient.

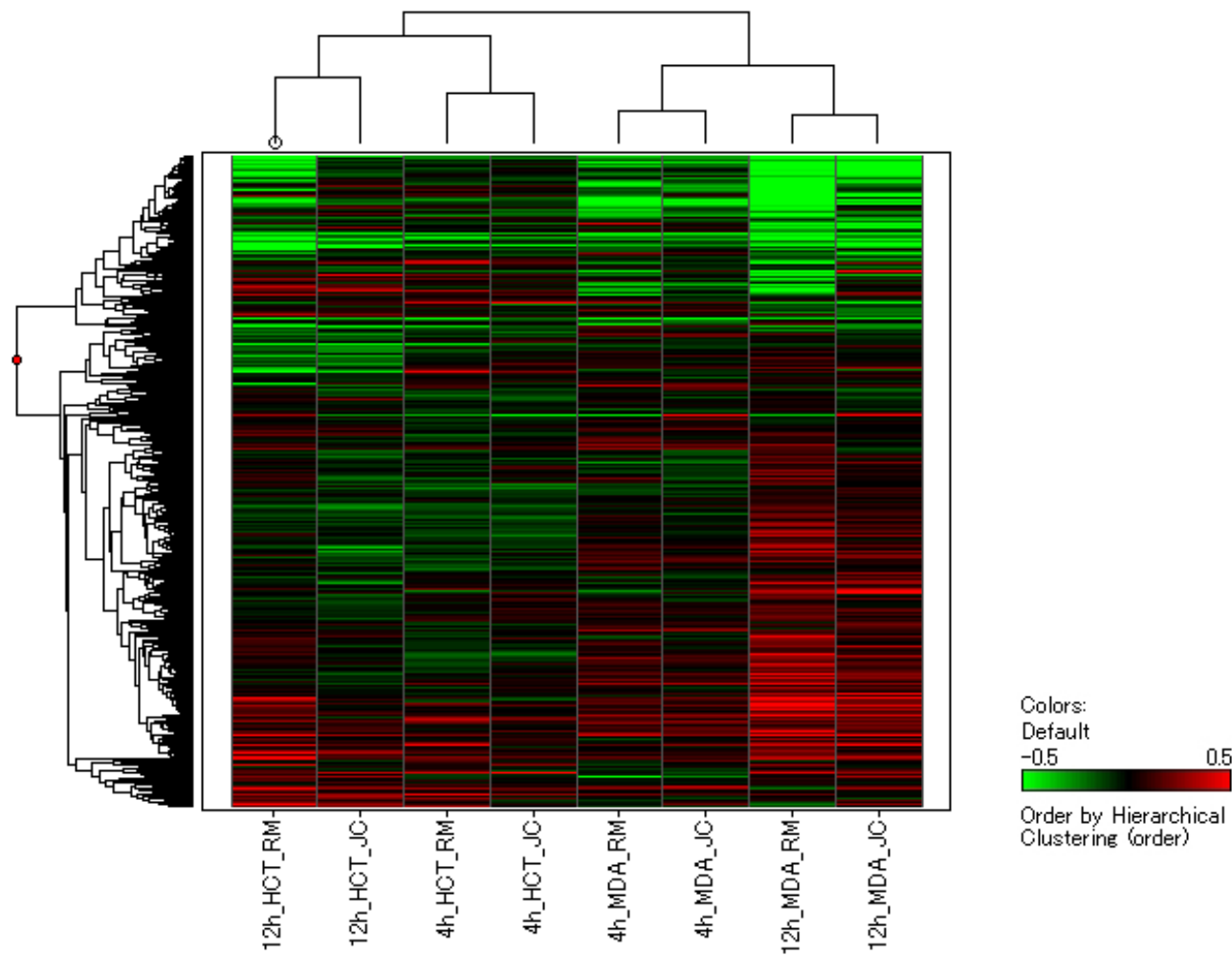

\begin{tabular}{|c|c|c|c|c|c|c|c|c|}
\hline & 4h_HCT_RM & 4h_HCT_JC & 4h_MDA_RM & 4h_MDA_JC & 12h_HCT_RM & 12h_HCT_JC & 12h_MDA_RM & 12h_MDA_JC \\
\hline 4h_HCT_RM & 1.00 & 0.66 & 0.21 & 0.32 & 0.41 & 0.44 & 0.18 & 0.24 \\
\hline 4h_HCT_JC & 0.66 & 1.00 & 0.12 & 0.19 & 0.29 & 0.30 & 0.12 & 0.15 \\
\hline 4h_MDA_RM & 0.21 & 0.12 & 1.00 & 0.74 & 0.34 & 0.00 & 0.65 & 0.44 \\
\hline 4h_MDA_JC & 0.32 & 0.19 & 0.74 & 1.00 & 0.41 & 0.20 & 0.50 & 0.46 \\
\hline 12h_HCT_RM & 0.41 & 0.29 & 0.34 & 0.41 & 1.00 & 0.57 & 0.50 & 0.59 \\
\hline 12h_HCT_JC & 0.44 & 0.30 & 0.00 & 0.20 & 0.57 & 1.00 & 0.00 & 0.18 \\
\hline 12h_MDA_RM & 0.18 & 0.12 & 0.65 & 0.50 & 0.50 & 0.00 & 1.00 & 0.76 \\
\hline 12h_MDA_JC & 0.24 & 0.15 & 0.44 & 0.46 & 0.59 & 0.18 & 0.76 & 1.00 \\
\hline
\end{tabular}

Venn diagrams in Figure 4 present the number of genes up- and down-regulated by at least twofold with statistical significance ( $\mathrm{p}$-value $<0.05$ ) by treatment with renieramycin $\mathrm{M}$ and jorunnamycin $\mathrm{C}$. The obtained results are summarized as follows: (i) transcriptional down-regulation was more predominant than up-regulation for both compounds irrespective of the cell lines and the time points in general; (ii) the numbers of genes significantly altered by treatment with renieramycin $\mathrm{M}$ and jorunnamycin C were larger in MDA-MB-435 than in HCT116, consistent with the order of cellular sensitivity to both compounds; (iii) significant overlap was observed between the genes altered by treatment with renieramycin $\mathrm{M}$ and jorunnamycin $\mathrm{C}$ in both cell lines; and (iv) the numbers of significantly altered genes in both cell lines were larger with renieramycin $\mathrm{M}$ treatment than with jorunnamycin $\mathrm{C}$ treatment, even though the drug concentrations for this analysis were corrected by 
using the $2 \times \mathrm{IC}_{50}$ values of both compounds. These observations indicate that the $\mathrm{C}-22$ ester side chain structure has a profound influence on the transcriptional perturbation by the renieramycin and jorunnamycin class of antitumor marine products.

Figure 4. Venn diagrams showing the numbers of altered genes at least two fold by treatment with renieramycin $M$ and jorunnamycin $C$ in HCT116 and MDA-MB-435. Abbreviations: RM, renieramycin M; JC, jorunnamycin C.

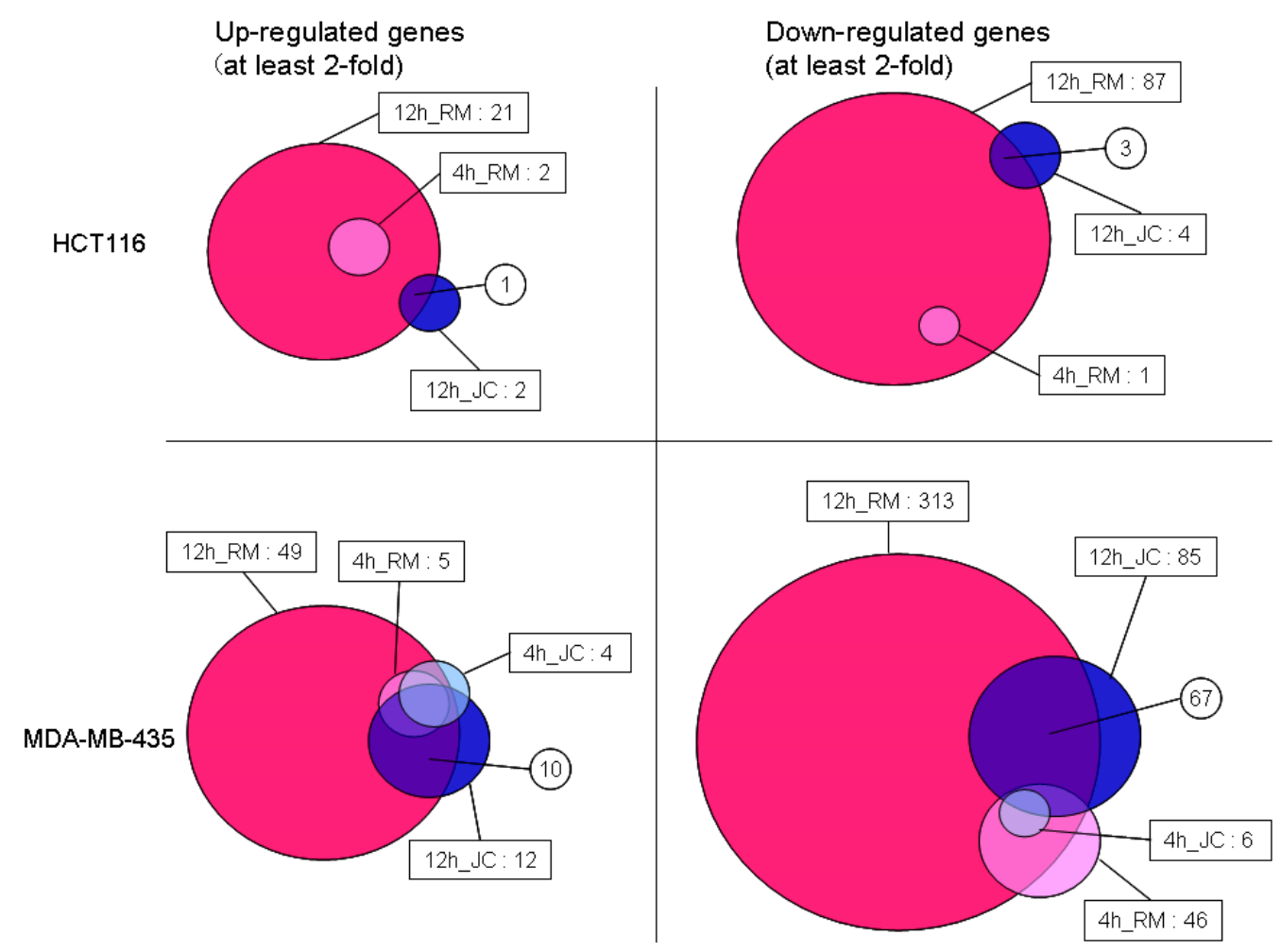

Figures 5 and 6 highlight the genes altered by at least twofold coordinately in HCT116 and MDA-MB-435 by 12-h treatment with renieramycin $\mathrm{M}$ or jorunnamycin C. The commonly up- or down-regulated genes between these two cell lines could be considered as biomarker candidates responsive to the cytotoxic effects of these compounds. In case of 12-h treatment with renieramycin $\mathrm{M}$, there were 8 and 37 genes were found to be up- and down-regulated, respectively. It is note worthy that GADD45A was found to be up-regulated in three reports describing expression profiles of ecteinascidin 743 treatment cell lines, human epithelioid cervix adenocarcinoma HeLa [6], human lung carcinoma A549 [9], and HCT116 \& MDA-MB-435 [12]. It is known that the transcription levels of GADD45A are increased following growth arrest and DNA-damage. This result strongly suggested that renieramycin $\mathrm{M}$ and jorunnamycin $\mathrm{C}$ have the similar G2/M arrest activities of ecteinascidin 743. On the other hand, down-regulated 37 genes of renieramycin $\mathrm{M}$ treatment experiments were subjected to GO (Gene Ontology) analysis to examine compound-associated biological processes, cellular components, and molecular functions. As the result, the following GO terms were enriched with p-values < 0.05: cell division, chromosome segregation, mitosis, and microtubule cytoskeleton organization and biogenesis in biological processes; intercellular junction and tight junction in cellular components; and diacylglycerol binding, guanylate kinase activity, and lipid binding in molecular 
functions (Figure 6). From this GO-biological processes analysis, it is suggested that renieramycin M may affect on mytotic phase of the cell cycle, which was also highlighted by the up-regulated GADD45A gene. GO analyses of the other set of expression level altered genes in common in both cell lines showed no significant enriched GO terms.

Figure 5. Genes up-regulated at least two fold coordinately in HCT116 and MDA-MB-435 by $12 \mathrm{~h}$ treatment with renieramycin M or jorunnamycin C. Abbreviations: HCT, HCT116; MDA, MDA-MB-435.

\section{Genes up-regulated at least 2-fold}

by $12-\mathrm{h}$ treatment with renieramycin $\mathrm{M}$

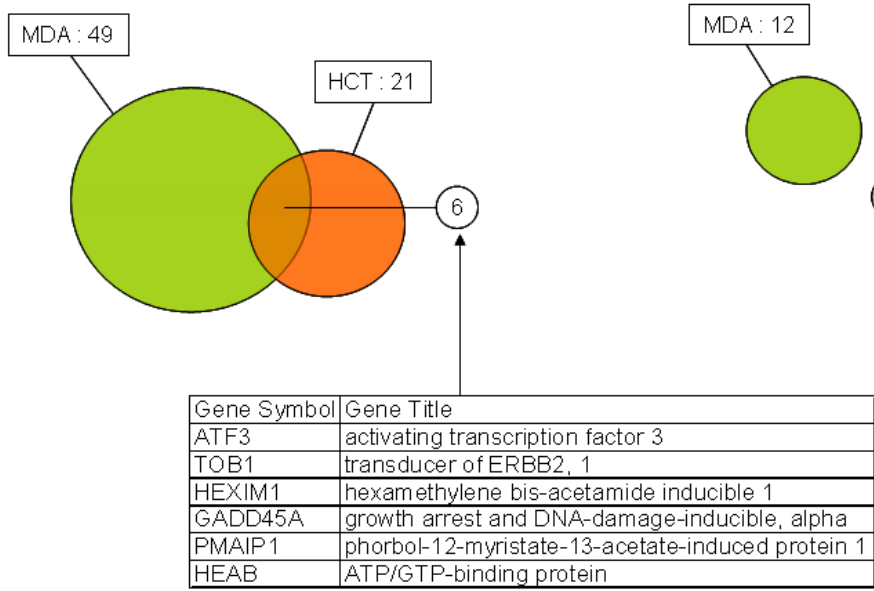

Figure 6. Genes down-regulated by at least two fold coordinately in HCT116 and MDA-MB-435 by 12 h treatment with renieramycin $\mathrm{M}$ or jorunnamycin C. Abbreviations: HCT, HCT116; MDA, MDA-MB-435; GO, gene ontology.

Genes down-regulated at least 2-fold

by $12-h$ treatment with renieramycin $M$

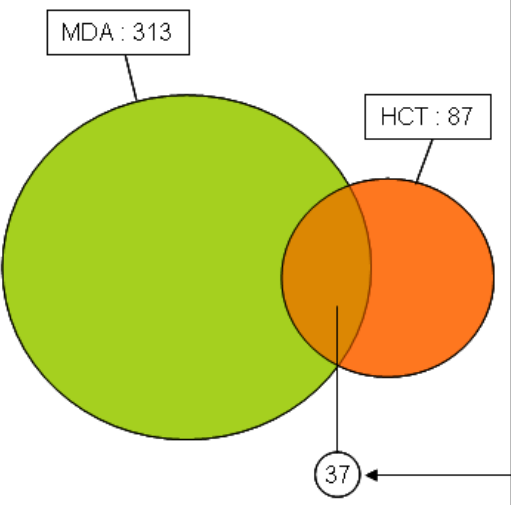

\begin{tabular}{|c|c|}
\hline PAFAH1B1 & platelet-activating factor acety/hydrolase, isoform lb, alpha subunit $45 \mathrm{kDa}$ \\
\hline MBNL1 & muscleblind-like (Drosophila) \\
\hline EAT & FAT tumor suppressor homolog 1 (Drosophila) \\
\hline PACSIN2 & protein kinase $\mathrm{C}$ and casein kinase substrate in neurons 2 \\
\hline DLG5 & discs, large homolog 5 (Drosophila) \\
\hline PKP4 & plakophilin 4 \\
\hline MYO10 & myosin $x$ \\
\hline TJP1 & tight junction protein 1 (zona occludens 1) \\
\hline TJP2 & tight junction protein 2 (zona occludens 2 ) \\
\hline MNTR1 & WW domain containing transcription requlator 1 \\
\hline STAG1 & stromal antigen 1 \\
\hline DLG1 & discs, large homolog 1 (Drosophila) \\
\hline ROCK2 & Rho-associated, coiled-coil containing protein kinase 2 \\
\hline PTPRK & protein tyrosine phosphatase, receptor type, $\mathrm{K}$ \\
\hline RAPGEF2 & Rap quanine nucleotide exchange factor (GEF) 2 \\
\hline$\overline{C D Y L}$ & chromodomain protein, Y-like \\
\hline SRPK2 & SFRS protein kinase 2 \\
\hline PPP2R5E & protein phosphatase 2 , requlatory subunit $B$ (B56), epsilon isoform \\
\hline MID1 & midline 1 (Opitz/BBB syndrome) \\
\hline PARN & polv(A)-specific ribonuclease (deadenylation nuclease) \\
\hline $\mathrm{DD} \times 10$ & DEAD (Asp-Glu-Ala-Asp) box polvpeptide 10 \\
\hline SMURF2 & SMAD specific E3 ubiquitin protein ligase 2 \\
\hline HMGA2 & high mobility group AT-hook 2 /// high mobility group AT-hook 2 \\
\hline MACF1 & microtubule-actin crosslinking factor 1 \\
\hline$\overline{\text { STK24 }}$ & serine/threonine kinase 24 (STE20 homolog, veast) \\
\hline TCF12 & transcription factor 12 (HTF4, helix-loop-helix transcription factors 4) \\
\hline STAG2 & stromal antigen 2 \\
\hline DYRK1A & dual-specificity tyrosine-(Y)-phosphorylation regulated kinase $1 \mathrm{~A}$ \\
\hline HNRPDL & heterogeneous nuclear ribonucleoprotein D-like \\
\hline GRB10 & growth factor receptor-bound protein 10 \\
\hline CTBP2 & C-terminal binding protein 2 \\
\hline ICALM & phosphatidylinositol binding clathrin assembly protein \\
\hline PIK3CB & phosphoinositide-3-kinase, catalytic, beta polvpeptide \\
\hline ROCK1 & Rho-associated, coiled-coil containing protein kinase 1 \\
\hline SYNCRIP & synaptotagmin binding, cytoplasmic RNA interacting protein \\
\hline $\mathrm{P}-2$ & |GF-|| mRNA-binding protein 2 \\
\hline
\end{tabular}


Figure 6. Cont.

\begin{tabular}{|c|c|c|}
\hline \multirow{14}{*}{ GO analysis } & \multicolumn{2}{|l|}{$\mathrm{BP}$} \\
\hline & Go term & genes \\
\hline & chromosome segregation & STAG1 STAG2 \\
\hline & mitosis & PAFAH1B1 STAG1 STAG2 \\
\hline & microtubule cytoskeleton organization and biogenesis & MID1 PAFAH1B1 \\
\hline & $\mathrm{CC}$ & \\
\hline & Go term & genes \\
\hline & intercellular iunction & DLG1 PKP4 T.JP1 T.JP2 \\
\hline & tight junction & TTJP1 TJJP2 \\
\hline & MF & \\
\hline & GO term & genes \\
\hline & diacylglycerol binding & RAPGEF2 ROCK1 ROCK2 \\
\hline & guanylate kinase activity & DLG1 T.JP2 \\
\hline & lipid binding & PICALM RAPGEF2 ROCK1 ROCK2 \\
\hline
\end{tabular}

by $12-\mathrm{h}$ treatment with jorunnamycin $\mathrm{C}$

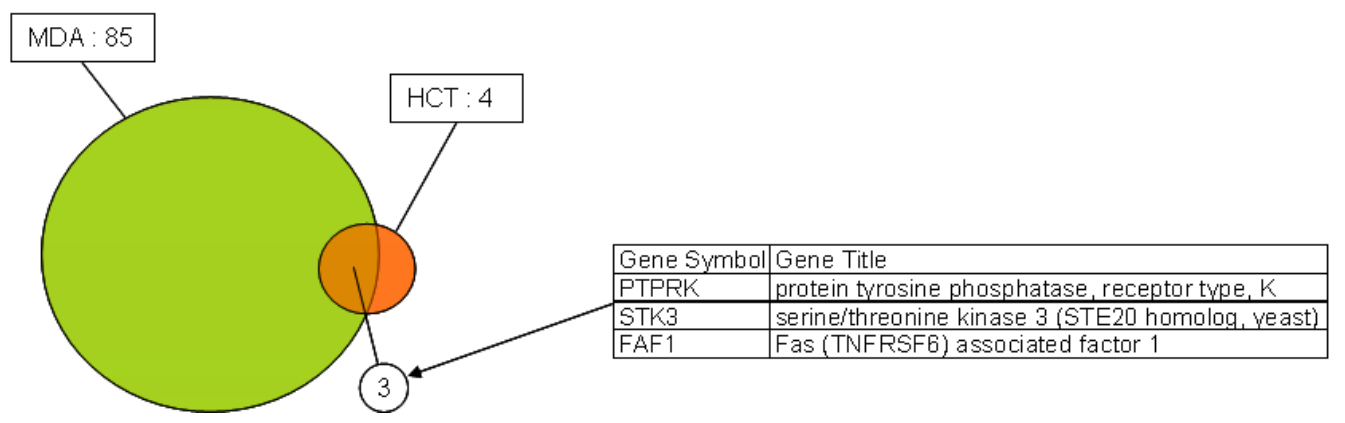

To select a set of biomarker genes in responsive to renieramycin $M$ and jorunnamycin $C$ treatments, the genes whose expression levels commonly altered in both cell lines with these two compounds were examined (Figure 7).

Figure 7. Identification of candidate biomarker genes down-regulated by at least two fold coordinately in HCT116 and MDA-MB-435 by $12 \mathrm{~h}$ treatments with renieramycin M and jorunnamycin $\mathrm{C}$.

Genes down-regulated at least 2-fold

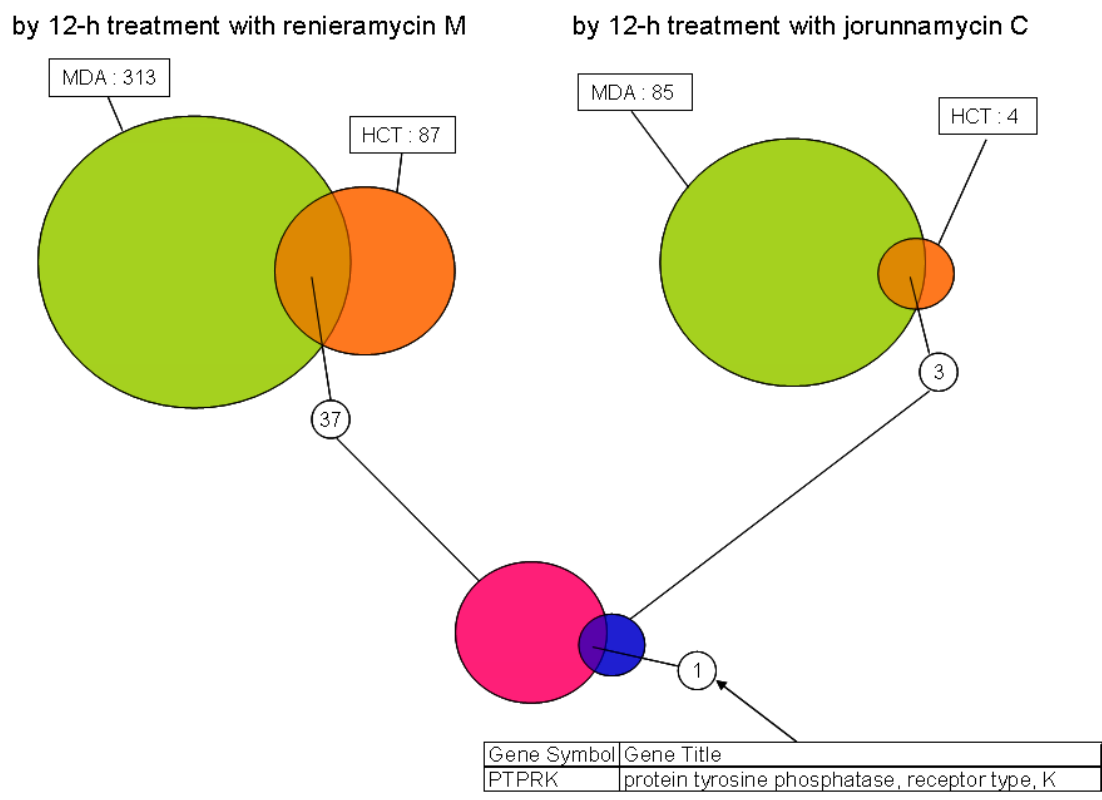


Within the list of down-regulated genes in 12-h treatments with both compounds, only one gene, $P T P R K$, was found to satisfy the selection criteria. The down-regulation of this gene seems to be involved in the primary mechanism(s) of action of both compounds, and is therefore considered to be a potential biomarker in response to the renieramycin and jorunnamycin class of antitumor marine products. PTPRK dephosphorylates EGFR and affects the downstream Erk activity. Xu et al. reported that overexpression of this gene in human keratinocytes decreased EGFR tyrosine phosphorylation, and resulted in near complete inhibition of growth [24]. This result is contrary to our expectation, however, the other PTPRs effects and kinase cascade cross-talks make the biological system to be complex, and the detailed PTPRK functions are still under the investigation. Martinez et al. reported that PTPRK is down-regulated in ecteinascidin 743 sensitive human sarcoma cells, on the contrary, it is up-regulated in resistant cells [25]. These findings support the idea that PTPRK gene is a potentially useful expression marker to monitor the antitumor effects of not only renieramycin $\mathrm{M}$ and jorunnamycin $\mathrm{M}$ but also a variety of naturally occurring isoquinolinequinones and their reduced forms with extremely potent antitumor activity.

\section{Conclusions}

We utilized oligonucleotide microarray analysis to profile the effects of renieramycin $\mathrm{M}$ and jorunnamycin $\mathrm{C}$ on cellular transcription, and found that the down-regulation of PTPRK gene can be a potentially useful biomarker in response to this class of unique antitumor marine products. The finding that renieramycin $\mathrm{M}$ is more potent against cancer cell growth than journnamycin $\mathrm{C}$ was also confirmed by the gene expression analysis, suggesting that the C-22 ester side chain structure should have a critical impact on not only the antiproliferative activity but also the transcriptional signatures of this class of unique antitumor natural products. This kind of microarray-based transcriptional SAR study represents a new and effective approach to drug discovery in the post-genomic era [26]. Effects to be examined of other types of cytotoxic molecules on the expression of PTPRK and compared with those of the ecteinascidin class of anticancer molecules are being made.

\section{Acknowledgements}

This research was partially supported by the Japan Society for the Promotion of Science (JSPS) AA Scientific Platform Program and a grant from the High-Tech Research Center Project, the Ministry of Education, Culture, Sports, Science and Technology (MEXT), Japan (S0801043). K. C. was sponsored by the Thailand Research Fund (TRF) for the 2003 Royal Golden Jubilee (RGJ) Ph. D. Program Scholarship (PHD/0157/2456). BNPME is supported by the Grant for Center of Excellence from the Commission on Higher Education, Thailand. We are grateful to JSPS and the National Research Cooperation of Thailand (NRCT) for supporting the collaboration between Thai and Japanese researchers in this work. 


\section{References and Notes}

1. Scott, J.D.; Williams, R.M. Chemistry and Biology of the Tetrahydroisoquionoline Antitumor Antibiotics. Chem. Rev. 2002, 102, 1669-1730.

2. Rinehart, K.L. Antitumor Compounds from Tunicates. Med. Drug. Rev. 2000, 20, 1-27.

3. Friedman, D.; Hu, Z.; Kolb, E.A.; Gorfajn, B.; Scotto, K.W. Ecteinascidin 743 Inhibits Activated but not Constitutive Transcription. Cancer Res. 2002, 62, 3377-3381.

4. Takebayashi, Y.; Pourquier, P.; Zimonjic, D.B.; Nakayama, K.; Emmert, S.; Ueda, T.; Urasaki, Y.; Kanzaki, A.; Akiyama, S.; Popescu, N.; Kraemer, K.H. Pommier, Antiproliferativity of Ecteinascidin 743 Is Dependent upon Transcription-Coupled Nucleotide-Excision Repair. Nat. Med. 2001, 7, 961-966.

5. Aune, G.J.; Furuta, T.; Pommier, Y. Ecteinascidin 743: A Novel Anticancer Drug with a Unique Mechanism of Action. Anticancer Drugs 2002, 13, 545-555.

6. Gajate, C.; An, F.; Mollinedo, F. Differential Cytostatic and Apoptotic Effects of Ecteinascidin743. J. Biol. Chem. 2002, 277, 41580-41589.

7. Jimeno, J.; Faircloth, G.; Fernandez Sousa-Faro, J.M.; Scheuer, P.J.; Rinehart, K. New Marine Derived Anticancer Therapeutics - A Journey from the Sea to Clinical Trials. Mar. Drugs 2004, 2, 14-29.

8. Fayette, J.; Coquard, I.R.; Alberti, L.; Ranchère, D.; Boyle, H.; Blay, J.Y. ET-743: A Novel Agent with Activity in Soft Tissue Sarcomas. Oncologist 2005, 10, 827-832.

9. David-Cordonnier, M.-H.; Gajate, C.; Olmea, O.; Laine, W.; de la Iglesia-Vicente, J.; Perez, C.; Cuevas, C.; Otero, G.; Manzanares, I.; Bailly, C.; Mollinedo, F. DNA and Non-DNA Targets in the Mechanism of Action of the Antitumor Drug Trabectedin. Chem. Biol. 2005, 12, 1201-1210.

10. Guirouin-Barbat, J.; Antony, S.; Pommier, Y. Zalypsis (PM00104) is a Potent Inducer of $\gamma$-H2AX foci and Reveals the Importance of the $\mathrm{C}$ Ring of Trabectedin for Transcription-coupled Repair Inhibition. Mol. Cancer Ther. 2009, 8, 2007-2014, also see http:/www.pharmamar.com/ en/pipeline/zalypsis.cfm.

11. Martinez, E.J.; Owa, T.; Schreiber, S.L.; Corey, E.J. Phthalascidin, a Synthetic Antitumor Agent with Potency and Mode of Action Comparable to Ecteinascidin 743. Proc. Natl. Acad. Sci. USA 1999, 96, 3496-3501.

12. Martinez, E.J.; Corey, E.J.; Owa, T. Antitumor Activity and Gene Expression-Based Profiling of Ecteinascidin 743 and Phthalascidin Pt 650. Chem. Biol. 2001, 8, 1151-1160.

13. Plowright, A.T.; Schaus, S.E.; Myers, A.G. Transcriptional Response Pathways in a Yeast Strain Sensitive Saframycin A and a More Potent Analog Evidence for a Common Based of Activity. Chem. Biol. 2002, 9, 607-618.

14. He, H.; Faulkner, D.J. Renieramycins E and F from the Sponge Reniera sp: Reassignment of the Stereochemistry of the Renieramycins. J. Org. Chem. 1989, 54, 5822-5824.

15. Frincke, J.M.; Faulkner, D.J. Antimicrobial Metabolites of the Sponge Reniera sp. J. Am. Chem. Soc. 1982, 104, 265-269.

16. Fontana, A.; Cavaliere, P.; Wahidulla, S.; Naik, C.G.; Cimino, G. A New Antitumor Isoquinoline Alkaloid from the Marine Nudibranch Jorunna funebris. Tetrahedron 2000, 56, 7305-7308. 
17. Suwanborirux, K.; Amnuoypol, S.; Plubrukarn, A.; Pummangura, S.; Kubo, A.; Tanaka, C.; Saito, N. Chemistry of Renieramycins. Part 3. Isolation and Structure of Stabilized Renieramycin Type Derivatives Possessing Antitumor Activity from Thai Sponge, Xestospongia Species Pretreated with Potassium Cyanide. J. Nat. Prod. 2003, 66, 1441-1446.

18. Amnuoypol, S.; Suwanborirux, K.; Pummangura, S.; Kubo, A.; Tanaka, C.; Saito, N. Chemistry of Renieramycins. Part 5. Structure Elucidation of Minor Components of Renieramycins $\mathrm{O}$ and Q-S, from Thai Marine Sponge, Xestospongia Species, Pretreated with Potassium Cyanide. J. Nat. Prod. 2004, 67, 1023-1028.

19. Charupant, K.; Daikuhara, N.; Saito, E.; Amnuoypol, S.; Suwanborirux, K.; Owa, T.; Saito, N. Chemistry of Renieramycins. Part 8. Synthesis and Cytotoxicity Evaluation of Renieramycin M-Jorunnamycin A Analogues. Bioorg. Med. Chem. 2009, 17, 4548-4558.

20. Charupant, K.; Suwanborirux, K.; Amnuoypol, S.; Saito, E.; Kubo, A.; Saito, N. Jorunnamycins A-C, New Stabilized Renieramycin-Type Bistetrahydroisoquinolines Isolated from the Thai Nudibranch Jorunna funebris. Chem. Pharm. Bull. 2007, 55, 81-86.

21. Mosmann, T. Rapid Colorimetric Assay for Cellular Growth and Survival: Application to Proliferation and Cytotoxicity Assays. J. Immunol. Methods 1983, 65, 55-63.

22. In vitro antiproliferative activity: Exponentially growing cells (1,500 cells per well for HCT116 and 3,000 cells per well for MDA-MB-435) were seeded into 96-well microtiter plates and precultured for one day. Both compounds (renieramycin $\mathrm{M}$ and jorunnamycin $\mathrm{C}$ ) were dissolved in dimethyl sulfoxide (DMSO) to make $20 \mathrm{mM}$ and further diluted with the culture medium to prepare threefold serial dilutions with the maximum concentration being $100 \mathrm{nM}$ after the addition into each well. The obtained dilutions were added to the plates and incubation was continued for an additional three days. The antiproliferative activity was measured in triplicate by the MTT colorimetric assay. Absorbance was measured with a TECAN microplate reader at a test wavelength of $540 \mathrm{~nm}$ and a reference wavelength of $660 \mathrm{~nm}$ to be taken as an index of the number of viable cells. The $\mathrm{IC}_{50}$ value (the concentration required to inhibit cell growth by $50 \%$ ) was determined by the least squares method.

23. Oligonucleotide microarray gene expression analysis: HCT116 and MDA-MB-435 cells were each plated at $2.0 \times 10^{6}$ cells per dish in 10 -cm-diameter dishes with $10 \mathrm{~mL}$ of fresh RPMI 1640 medium. After $24 \mathrm{~h}$ pre-incubation, HCT116 cells were treated with $2 \times \mathrm{IC}_{50}$ concentration of each test compound (33 nM renieramycin $\mathrm{M}$ or $55 \mathrm{nM}$ jorunnamycin $\mathrm{C}$ ) for $4 \mathrm{~h}$ and $12 \mathrm{~h}$. MDAMB-453 cells were also treated with $2 \times \mathrm{IC}_{50}$ concentration of each test compound (13 nM renieramycin $\mathrm{M}$ or $33 \mathrm{nM}$ jorunnamycin $\mathrm{C}$ ) for $4 \mathrm{~h}$ and $12 \mathrm{~h}$. DMSO (0.2\%) treatment was used as control. Total RNA was extracted from the cells using Trizol (Invitrogen). The extracted RNA was purified using an RNeasy kit (Qiagen). Double-stranded cDNA was synthesized from $5 \mu \mathrm{g}$ of total RNA by means of a SuperScript double-stranded cDNA synthesis kit (Invitrogen) with T7-d(T) 24 primer. The cDNA product was purified by phenol/chloroform/isoamyl alcohol extraction. In vitro transcription was carried out by means of a GeneChip IVT Labeling kit (Affymetrix). The resulting biotin-labeled cRNA was purified using the RNeasy kit. cRNA was fragmented at $94{ }^{\circ} \mathrm{C}$ for $35 \mathrm{~min}$, and then hybridized for 16 h onto an Affymetrix GeneChip Human Genome Focus array that is capable of probing approximately 8,500 transcripts. The probe arrays were washed and stained with streptavidin-phycoerythrin and biotinylated goat 
anti-streptavidin on an Affymetrix Fluidics Station. Fluorescence intensities were captured with a Hewlett-Packard confocal laser scanner. All quantitative data were processed using the robust multi-array average (RMA) method [27], and transcriptional signature was defined as the differences between the data for compound treatment and those for DMSO treatment (control) on a logarithmic scale. Hierarchical clustering of the obtained transcriptional signatures for all test samples was done using the unweighted pair grouping method with arithmetic mean (UPGMA) in GeneSpring software to afford a dendrogram (tree graph) based on the similarity (cosine correlation). Up- and down-regulated genes were selected according to the following criteria: i) at least twofold change compared with control data; and ii) statistical significance with p-value $<0.05$ by the t-test in triplicate data. Gene Ontology (GO) analysis was used to illuminate compound-related biological processes, cellular components, and molecular functions. Enriched GO terms with Benjamini-Hochberg adjusted p-values $<0.05$ were selected using the Bioconductor GOstats library [28].

24. Xu, Y.; Tan, L.J.; Grachtchouk, V; Voorhees, J.J.; Fisher, G.J. Receptor-type Protein-tyrosine Phosphatse-K regulates Epidermal Growth Factor Receptor Function. J. Biol. Chem. 2005, 280, 42694-42700.

25. Martínez, N.; Sánchez-Beato, M.; Carnero, A.; Moneo, V.; Tercero, J.C.; Fernández, I.; Navarrete, M.; Jimeno, J.; Piris, M.A. Transcriptional Signature of Ecteinascidin 743 (Yondelis, Trabectedin) in Human Sarcoma Cells Explanted from Chemo-Naive Patients. Mol. Cancer Ther. 2005, 4, 814-823.

26. Owa, T.; Yokoi, A.; Yamazaki, K.; Yoshimatsu, K.; Yamori, T.; Nagasu, T. Array-Based Structure and Gene Expression Relationship Study of Antitumor Sulfonamide Including $N$-[2-(4-hydroxyphenyl)amino]3-pyridinyl]-4-methoxybenzenesulfonamide and $N$-(3-Chloro-7indolyl)-1,4-benzenedisulfonamide. J. Med. Chem. 2002, 45, 4913-4922.

27. Irizarry, R.A.; Hobbs, B.; Collin, F.; Beazer-Barclay, Y.D.; Antonellis, K.J.; Scherf, U. Exploration, Normalization, and Summaries of High Density Oligonucleotide Array Probe. Biostatistic 2003, 4, 249-264.

28. Gentleman, R. Using GO for Statistical Analyses. In Proceedings of COMPSTAT 2004 Symposium, 2004; pp. 171-180, also see http://comostat2004.cuni.cz/.

Samples Availability: Available from the authors.

(C) 2009 by the authors; licensee Molecular Diversity Preservation International, Basel, Switzerland. This article is an open-access article distributed under the terms and conditions of the Creative Commons Attribution license (http://creativecommons.org/licenses/by/3.0/). 